\title{
Glycoproteins from Mature Human Milk Whey
}

\author{
ANATOLY BEZKOROVAINY(27) AND JAMES H. NICHOLS \\ Department of Biochemistry, Rush Medical College, Rush-Presbyterian-St. Luke's Medical Center, \\ Chicago, Illinois, USA
}

\section{Extract}

Two milk-specific glycoprotein fractions and serum orosomucoid were isolated from mature human milk. One of the milk-specific glycoproteins was homogeneous and was termed glycoprotein A. Its sedimentation and diffusion constants were $2.6 \mathrm{~S}$ and $6.3 \mathrm{~F}$, respectively, giving a molecular weight of 29,500 . It contained some $70 \%$ carbohydrate consisting of sialic acid, galactose, fucose, glucosamine, and galactosamine. It was not immunologically related to serum orosomucoid. The other glycoprotein, called glycoprotein B, was heterogeneous with an average molecular weight of near 4,000 , and carbohydrate comprised some $75 \%$ of its weight. Both glycoprotein fractions supported the growth of Lactobacillus bifidus var. Penn. Removal of sialic acid enhanced the growth-promoting activity of glycoprotein $B$ but not of $A$.

\section{Speculation}

Mature human milk whey contains a number of glycoproteins that stimulate the growth of $L$. bifidus var. Penn. These glycoproteins may act in concert with the well known oligosaccharides to maintain an acid environment in the infant's gastrointestinal tract.

Mature human milk contains a number of carbohydrate-containing proteins (glycoproteins) possessing a diversity of biologic functions. Perhaps the best characterized of such proteins is lactoferrin, a non-heme iron-binding protein. It has some $7.2 \%$ of carbohydrate (16). Another glycoprotein isolated from human milk is $\kappa$-casein, an $\alpha$-casein-stabilizing factor similar to cow's milk $k$-casein (13). Of serum glycoproteins, human milk contains considerable amounts of immunoglobulins (6), and immunologic testing has revealed the presence of trace amounts of other glycoproteins, such as transferrin, haptoglobin, and orosomucoid (11).

Human colostrum has, in addition, been shown to contain a number of acid glycoproteins with $L$. bifidus growth-promoting activities $(12,15)$. These have generally contained high amounts of carbohydrate (near 75\%). Bovine colostral acid glycoproteins (3) do not possess the L. bifidus growth-promoting activity (15).

Both human mature milk and colostrum were shown to contain various oligosaccharides that promote the growth of $L$. bifidus (10); however, no reports seem to be available regarding the presence in milk of acid glycoproteins of the type seen in the colostrums of human beings and of cows. In view of the alleged importance of the $L$. bifidus growth factors in regard to infant health and nutrition $(8,9)$, it seemed worthwhile to investigate the possible existence of acid glycoproteins in human mature milk, which, in addition to the well known oligosaccharides, might support the growth of $L$. bifidus. The present paper describes the isolation of one such glycoprotein, as well as serum orosomucoid, and shows the presence in human milk of other glycoproteins with similar chemical properties.

\section{MATERIALS AND METHODS}

\section{HUMAN MILK}

Mature human milk was obtained from private donors or from a milk bank. The individual samples were defatted immediately after collection and frozen for purposes of storage. When required, the samples were thawed at $4^{\circ}$, and the whey was prepared by acidifying the skim milk as described previously (3).

Orosomucoid was prepared from human serum as described previously (5). Its antiserum (rabbit) was purchased from Hyland Laboratories (2l). Sephadex gel chromatography media were acquired from Parmacia Corp. (22) and CM-cellulose was bought from Sigma Chemical Co. (23). Agar used in agar gel electrophoresis and Ouchterlony-type double diffusion experiments was obtained from Difco Laboratories (24).

All common laboratory chemicals were of reagent grade quality and were obtained from Fisher Scientific Co. (25).

\section{FRACTIONATION PROCEDURES}

Ammonium sulfate fractionations of whey proteins were performed in an ice bath at or near neutral $\mathrm{pH}$. All precipitates were removed by centrifugation in a Sorvall $\mathrm{RC}-2 \mathrm{~B}$ centrifuge at 8,000 $\mathrm{rpm}$. Each precipitate was redissolved in water, dialyzed exhaustively against distilled water, and freeze-dried.

Gel filtration with Sephadex G-25 was carried out at $4^{\circ}$ with water as the eluant using a column $(2.5 \times 50 \mathrm{~cm})$. The rate of flow was $12 \mathrm{ml} / \mathrm{hr}$ with $6-\mathrm{ml}$ fractions being collected every $30 \mathrm{~min}$. The void volume was $70 \mathrm{ml}$. Gel filtration on Sephadex G-200 was performed as above, except that $0.1 \mathrm{M} \mathrm{NaHCO}_{3}$ was used as the eluant, and the flow rate of $6 \mathrm{ml} / \mathrm{hr}$ with $3-\mathrm{ml}$ fractions being collected every $30 \mathrm{~min}$. The void volume of the Sephadex G-200 column was also $70 \mathrm{ml}$.

Chromatography on CM-cellulose was done as previously described $(3,5)$.

Every fraction eluted was tested for carbohydrate by the phenol- $\mathrm{H}_{2} \mathrm{SO}_{4}$ method (7) and for absorption at $280 \mathrm{~nm}$.

\section{ANALYTICAL METHODS}

Agar gel electrophoresis was performed by the method of Zschocke (20), where agar concentration was $1.25 \%$. Moving boundary electrophoresis was done in an Antweiler microelectrophoresis apparatus as described previously (2). Protein concentrations were $3 \%$ in $0.05 \mathrm{M}$ sodium Veronal $-0.035 \%$ ethylene diamine tetra-acetic acid buffer at $\mathrm{pH}$ 8.6. Ultracentrifugation was carried out in a Spinco model $E$ centrifuge in synthetic boundary cells at protein concentrations of $3-10 \mathrm{mg} / \mathrm{ml}$ using $0.1 \mathrm{M} \mathrm{NaHCO}_{3}$ as a solvent. The temperature was $20^{\circ}$. Sedimentation coefficients, calculated according to the method of Schachman (17), were plotted against concentrations, and the curve was extrapolated to zero concentration to obtain the sedimentation constant. The 
diffusion constant was determined in a Spinco model $\mathrm{H}$ apparatus, equipped with interference fringe optics, at $2.7^{\circ}$ and also at several protein concentrations $(0.8-3 \mathrm{mg} / \mathrm{ml})$ using the $0.1 \mathrm{M} \mathrm{NaHCO}_{3}$ solvent. The diffusion coefficients were plotted against concentrations and curve was extrapolated to zero concentration to obtain the diffusion constant. Partial specific volumes were determined from composition as described by Schachman (17). Molecular weights were calculated by the sedimentation-diffusion method (17). Other physical methods used were those described previously (14), as were quantitations of amino acids and carbohydrates and the method for identification of hexoses.

Immunochemical assays for orosomucoid were done by the Ouchterlony-type double diffusion procedure as described previously (19).

\section{LACTOBACILLUS BIFIDUS VAR. PENN. GROWTH}

The growth-promoting activities of the various glycoproteins were tested as described previously (15). Results were expressed in terms of the number of milliliters of $0.1 \mathrm{~N} \mathrm{NaOH}$ required to titrate the acid produced by the bacterial growth $\left(40 \mathrm{hr}\right.$ at $\left.37^{\circ}\right)$ in 5 $\mathrm{ml}$ medium in the presence of $100 \mu \mathrm{g}$ material tested. The growth response curve was linear in that glycoprotein concentration region.

\section{RESULTS}

\section{ISOLATION OF GLYCOPROTEIN-CONTAINING FRACTIONS}

Human milk whey was fractionated by ammonium sulfate using volumes of $200-400 \mathrm{ml}$ whey each. A total of seven whey lots from three different donors were fractionated with substantially identi-

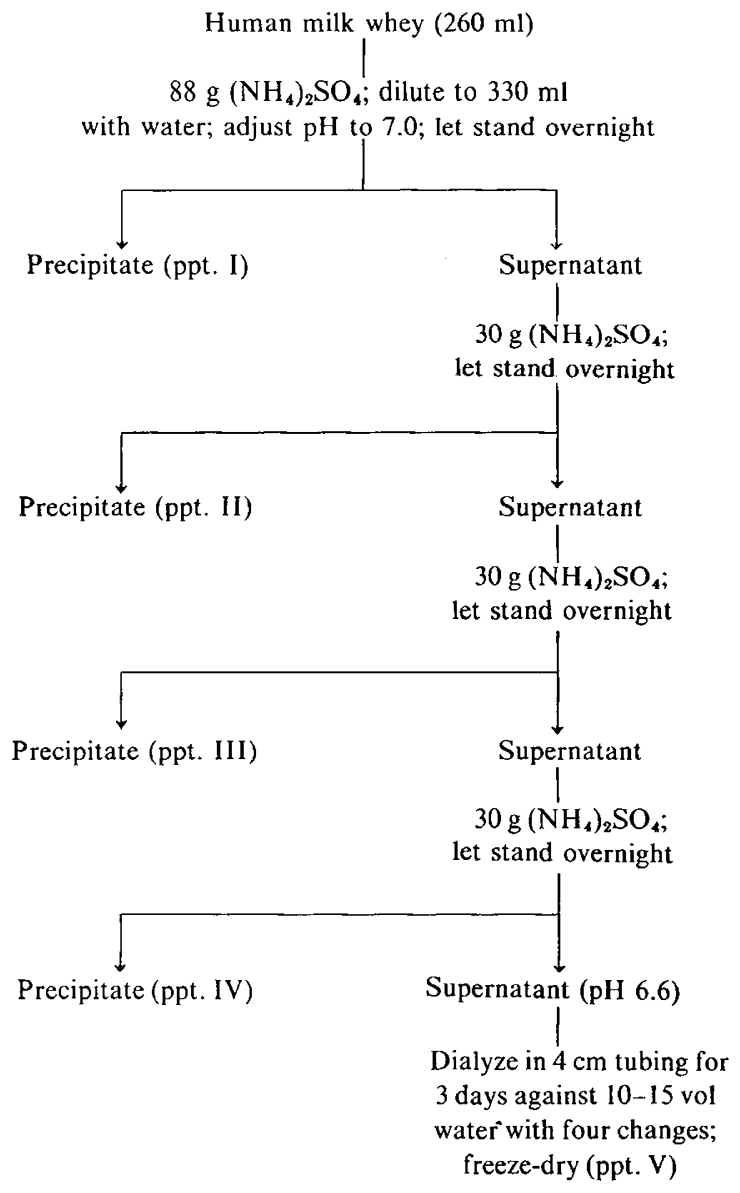

Fig. I. Fractionation of a representative sample of human milk whey with ammonium sulfate. All salt additions were done in an ice bath, and centrifugations, dialyses, and "standing" were performed at $4^{\circ}$.
Table 1. Properties of ammonium sulfate fractions of human milk whey 1

\begin{tabular}{lcc}
\hline \multicolumn{1}{c}{ Fraction } & $\begin{array}{c}\text { Yield, mg from 260 } \\
\text { ml whey }\end{array}$ & Hexose + fucose, $\%^{2}$ \\
\hline Ppt. I & 823 & 5.8 \\
Ppt. II & 584 & 4.2 \\
Ppt. III & 263 & 4.8 \\
Ppt. IV & 46 & 7.8 \\
Ppt. V & 254 & 51.0 \\
\hline
\end{tabular}

${ }^{1}$ Precipitate (ppt.) I was precipitated at $2 \mathrm{M}$ concentration, whereas ppt. II was precipitated at $2.6 \mathrm{M}\left(\mathrm{NH}_{4}\right)_{2} \mathrm{SO}_{4}$. Ppt. IV was precipitated at near saturation of $\left(\mathrm{NH}_{4}\right)_{2} \mathrm{SO}_{4}$, and ppt. $\mathrm{V}$ is nondialyzable material soluble in saturated $\left(\mathrm{NH}_{4}\right)_{2} \mathrm{SO}_{4}$ solution.

${ }^{2}$ By the orcinol reaction (18).

cal results. A representative process is produced in Figure 1.

All fractions thus obtained were subjected to agar gel and moving boundary electrophoresis and carbohydrate analysis (orcinol reaction, Reference 18 ). These results are summarized in Table 1.

Electrophoretic analyses of these fractions revealed that precipitate (ppt.) I consisted largely of material remaining at the origin and some material moving cathodally. Ppt. II consisted of lactoferrin and $\alpha$-lactalbumin, whereas ppt. III had $\alpha$-lactalbumin, serum albumin, and some lactoferrin. Ppt. IV contained some $\alpha$-lactalbumin, a component moving like serum $\alpha_{1}$-globulin and material moving faster than serum albumin. The components of ppt. V were stained very faintly, and this fraction was submitted to moving boundary electrophoresis. The latter showed the presence of two components: one moving like the $\alpha_{1}$-globulin (orosomucoid), the other migrating like serum $\beta$-globulin at $\mathrm{pH} 8.6$.

Table $\mathbf{l}$ indicated that ppt. IV and $\mathrm{V}$ were rich in carbohydrate, and this paper is concerned with the components of these two fractions.

\section{OROSOMUCOID}

Orosomucoid has been detected in mature human milk by immunochemical means (11), and from our previous experience with this protein (4), it was expected that orosomucoid would appear in ppt. IV. This fraction $(120 \mathrm{mg})$ was, therefore, chromatographed on CM-cellulose as described previously $(4,5)$, and the breakthrough fraction $(24 \mathrm{mg})$ was subjected to various analyses to ascertain its nature.

This component of ppt. IV moved like orosomucoid both in agar gel and moving boundary electrophoretic systems. Its carbohydrate composition was identical with that of orosomucoid, and in the Ouchterlony double diffusion, it gave a precipitin line with orosomucoid antiserum, which coalesced with that given by authentic orosomucoid. It was concluded that the protein isolated from ppt. IV was indeed serum orosomucoid.

\section{ISOLATION OF TWO MILK-SPECIFIC COMPONENTS OF GLYCOPROTEIN NATURE FROM PPT. V}

Ppt. V was dissolved in water and subjected to gel filtration on a column of Sephadex G-25 using water as the developing solvent. The results are given in Figure 2. The fraction indicated was rechromatographed in the same system, and was then subjected to gel filtration on Sephadex G-200 column using $0.1 \mathrm{M} \mathrm{NaHCO}_{3}$ as the developing solvent. Two carbohydrate-rich fractions were separated, and termed A and B. Both were rechromatographed on Sephadex G-200 medium under the above conditions, dialyzed against distilled water, and freeze-dried.

Glycoprotein A was homogeneous in the ultracentrifuge by the method of agar gel electrophoresis and by moving boundary electrophoresis at $\mathrm{pH}$ 8.6. Its electrophoretic migration at that $\mathrm{pH}$ was identical with that of human serum orosomucoid. Glycopro- 


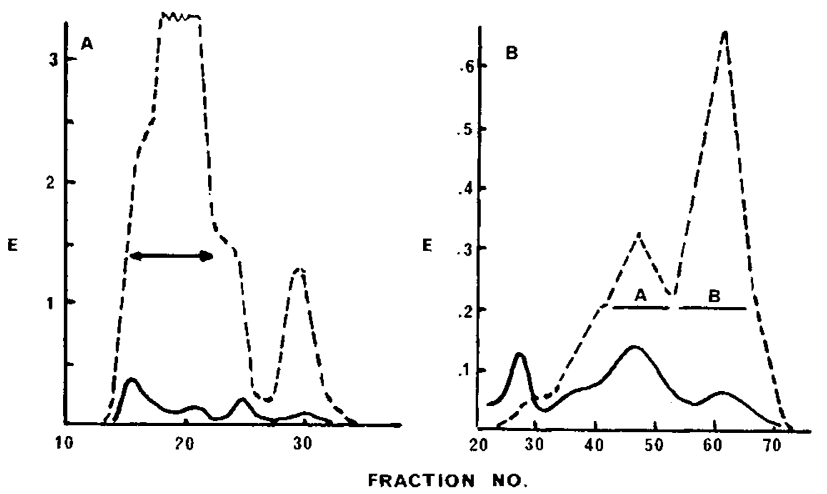

Fig. 2. Gel chromatography of the precipitate (ppt.) V fraction of human milk whey. Broken lines indicate the distribution of carbohydrate, whereas the continuous lines indicate absorption at $280 \mathrm{~nm}$. Frame A: chromatography of ppt. V on Sephadex G-25 using water as irrigant. Amount applied was $225 \mathrm{mg}$, amount recovered in fraction indicated by arrows was $166 \mathrm{mg}$. After rechromatography under the same conditions, $150 \mathrm{mg}$ were recovered. Frame $B$ : chromatography of the fraction indicated in Frame $A$ on a Sephadex G-200 column. Amount applied was $168 \mathrm{mg}$, amounts recovered in fractions (glycoproteins) A and B were 48.0 and $75 \mathrm{mg}$, respectively.

tein B also showed a single peak in the ultracentrifuge; however, upon agar gel electrophoresis, it showed the presence of at least two components migrating faster than human serum albumin, and upon prolonged moving boundary electrophoresis, three components were observed, whose migration was that of $\beta$-globulin, slow $\beta$-globulin, and $\gamma$-globulin.

The physical properties of the two components of ppt. $\mathrm{V}$ are summarized in Table 2, and their compositions are given in Table 3. It is seen that the physical parameters of glycoprotein A were very similar to those of a colostrum glycoprotein previously isolated (14); however, it did differ from the colostrum glycoprotein in its amino acid and carbohydrate composition.

The nature of the carbohydrate moieties of the two glycoproteins was further investigated by mild acid hydrolysis. After hydrolysis with $2 \mathrm{M} \mathrm{HCl}$ for $10 \mathrm{hr}$ at $100^{\circ}$, the samples were placed on a "medium" column of the amino acid analyzer, and the glucosamine to galactosamine ratios were determined. These proved to be 8:1 for glycoprotein A and 50:1 for glycoprotein B.

The nature of the hexose was determined by first hydrolyzing the glycoproteins with $1 \mathrm{M} \mathrm{HCl}$ for $4 \mathrm{hr}$ at $100^{\circ}$ (2-mg sample in $1 \mathrm{ml}$ acid) then subjecting the dried sample to paper chromatography in the butanol-pyridine-water (4:3:2) system. Glycoprotein A showed galactose only, whereas glycoprotein $B$ showed galactose and

Table 2. Physical properties of two glycoproteins isolated from human milk whey precipitate (ppt.) $V^{1}$

\begin{tabular}{lcc}
\hline & \multicolumn{2}{c}{ Glycoprotein } \\
\cline { 2 - 3 } & A & B \\
\hline Sedimentation constant $\left(s_{20, \mathrm{w}}^{0}\right)$ & 2.6 & 0.95 \\
Diffusion constant $\left(D_{20, \mathrm{w}}^{\mathrm{N}}\right)$ & 6.3 & 15.9 \\
Partial specific volume $(\overline{\mathrm{V}})$ & 0.662 & 0.650 \\
Molecular weight $^{2}$ & 29,500 & 4,200 \\
\hline
\end{tabular}

${ }^{1}$ Ultracentrifugation was done in a Spinco model $\mathrm{E}$ ultracentrifuge using synthetic boundary cells at $20^{\circ}$; the diffusion constant was determined in a Spinco model $\mathrm{H}$ apparatus at $2.7^{\circ}$. Solvent in both cases was $0.1 \mathrm{~N} \mathrm{NaHCO}_{3}$. The partial specific volume was calculated from composition, and molecular weight was calculated by the sedimentation-diffusion method.

${ }^{2}$ Apparent weight average molecular weight for glycoprotein B, as it is a mixture of three components.
Table 3. Amino acid and carbohydrate composition of two glycoproteins isolated from human milk whey precipitate (ppt.) $V^{\mathbf{1}}$

\begin{tabular}{|c|c|c|c|}
\hline \multirow[b]{3}{*}{$\begin{array}{l}\text { Amino acid or } \\
\text { monosaccharide }\end{array}$} & \multicolumn{3}{|c|}{ Glycoprotein } \\
\hline & \multicolumn{2}{|c|}{ A } & \multirow{2}{*}{$\begin{array}{c}B \\
g / 100 g\end{array}$} \\
\hline & $\mathrm{g} / 100 \mathrm{~g}$ & $\begin{array}{l}\text { Residues/ } \\
\text { molecule }\end{array}$ & \\
\hline Lysine & 0.6 & 1 & 1.0 \\
\hline Histidine & 0.6 & 1 & 0.9 \\
\hline Arginine & 0.6 & 1 & 0.2 \\
\hline Aspartic acid & 2.9 & 7 & 4.9 \\
\hline Threonine & 4.0 & 12 & 0.8 \\
\hline Serine & 2.3 & 8 & 3.7 \\
\hline Glutamic acid & 2.5 & 6 & 4.5 \\
\hline Proline & 4.0 & 12 & 0.8 \\
\hline Glycine & 1.9 & 10 & 1.7 \\
\hline Alanine & 2.1 & 9 & 1.7 \\
\hline Valine & 2.6 & 8 & 1.0 \\
\hline Methionine & 0.0 & & 0.5 \\
\hline Isoleucine & 0.9 & 2 & 0.7 \\
\hline Leucine & 0.9 & 2 & 0.9 \\
\hline Tyrosine & 0.6 & 1 & 0.3 \\
\hline Phenylalanine & 0.6 & 1 & 0.3 \\
\hline $\mathrm{N}$-Acetylneuraminic acid & 5.5 & 6 & 6.7 \\
\hline Hexose & 28.0 & 51 & 32.0 \\
\hline Methylpentose & 8.1 & 16 & 11.0 \\
\hline Hexosamine $^{2}$ & 28.5 & 42 & 26.5 \\
\hline
\end{tabular}

${ }^{1}$ There was no half-cystine or tryptophan in either glycoprotein. Hydrolysis was performed in $5.8 \mathrm{M} \mathrm{HCl}$ at $110^{\circ}$ for $24 \mathrm{hr}$ in sealed tubes under $\mathrm{N}_{2}$ atmosphere. Amino acid values were corrected by the method of Anderson et al. (1). Carbohydrates were determined as described in Methods. All analyses were done in triplicate and the results averaged.

${ }^{2}$ Glucosamine to galactosamine ratio for glycoprotein A was 8:1.

traces of glucose, but no mannose. Both glycoproteins showed the presence of fucose (Fig. 3).

Neither glycoprotein fraction A nor B gave a precipitin line with human serum orosomucoid antiserum.

\section{BIOLOGIC PROPERTIES OF MILK WHEY GLYCOPROTEINS}

Both glycoproteins A and B were tested for their ability to promote the growth of $L$. bifidus var. Penn. The results are given in Table 4. It is apparent that glycoprotein A gave a considerable bacterial growth-promoting activity, which was at the same level as those of the colostrum glycoproteins described previously (15). Glycoprotein B, on the other hand, have a very low L. bifidus growth-promoting activity that was, contrary to that glycoprotein A, increased upon desialization.

\section{DISCUSSION}

This paper indicates that mature human milk contains relatively large quantities of serum orosomucoid, as well as milk-specific glycoproteins with carbohydrate content much greater than that of either orosomucoid or cow's milk and colostrum glycoproteins. In many respects, glycoprotein A was very similar to the human colostrum glycoprotein previously isolated (14); both had molecular weights of near 30,000 and some $70 \%$ total carhohydrate, and both had $L^{*}$. bifidus growth-promoting activities. In addition, both had nearly identical number of hexose, fucose, and hexosamine residues per molecule of glycoprotein, although the milk protein had only half as much sialic acid, and its glucosamine to galactosamine ratio was $8: 1$ instead of $3: 1$ as in the colostrum material. There were differences in amino acid composition values, especially in regard to aspartic acid, threonine, and glycine. 


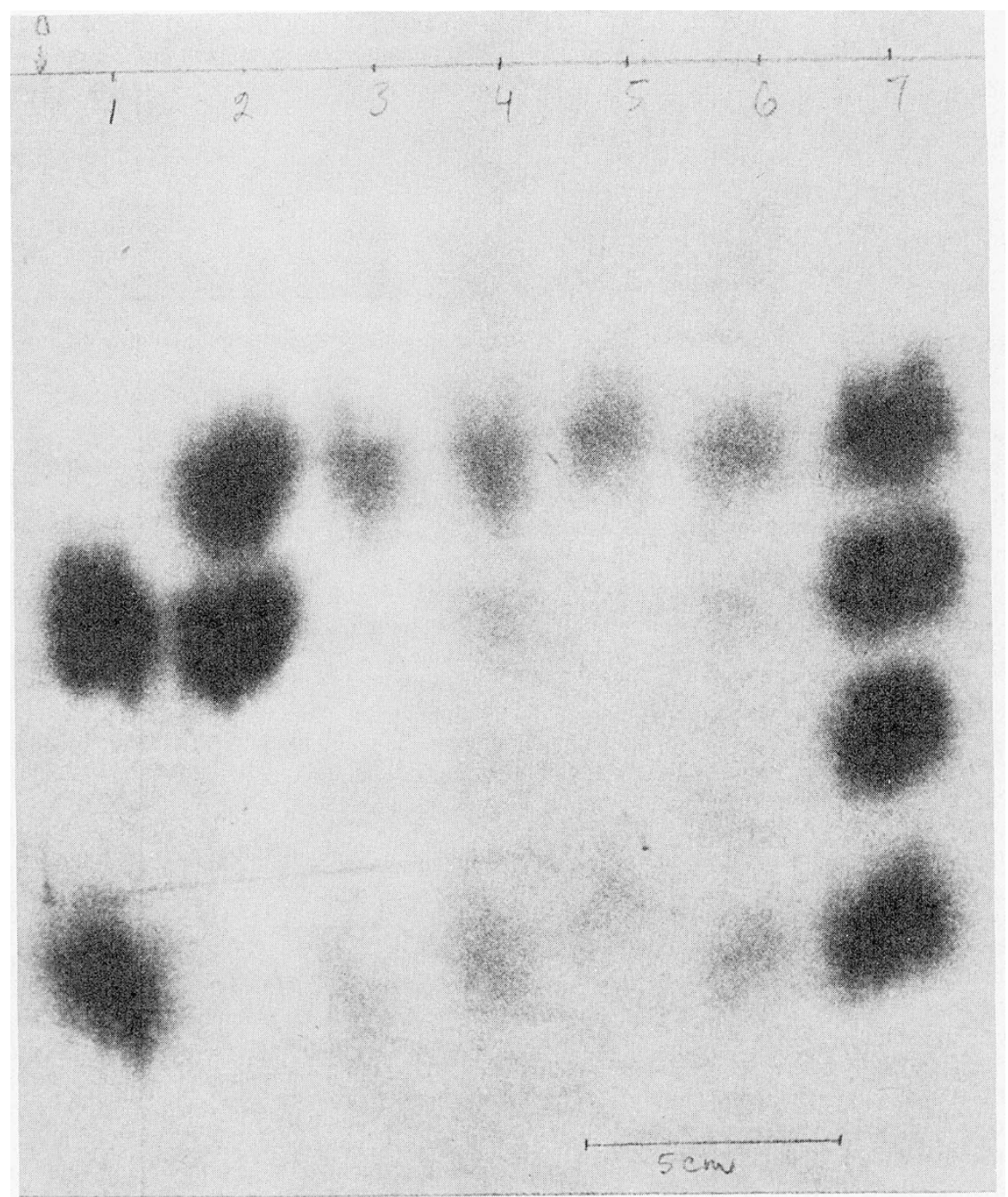

Fig. 3. Descending paper chromatographic analysis of monosaccharides from glycoproteins A and B. In descending order, channel 1 had glucose and fucose; 2, galactose and glucose; 3 and 5, glycoprotein A; 4 and 6, glycoprotein B; 7, galactose, glucose, mannose, and fucose. Actual migration of the glucose spot was $25 \mathrm{~cm}$ in this experiment.

Table 4. Lactobacillus bifidus var. Penn. growth-promoting activities of human whey glycoproteins $A$ and $B^{1}$

\begin{tabular}{lcc}
\hline \multicolumn{1}{c}{ Compound } & $\begin{array}{c}\text { Native } \\
\text { material }\end{array}$ & $\begin{array}{c}\text { Desialyzed } \\
\text { material }\end{array}$ \\
\hline Glycoprotein A & 4.4 & 4.9 \\
Glycoprotein B & 0.7 & 1.2 \\
Dialyzed human milk solids & 0.3 & \\
\hline
\end{tabular}

${ }^{1}$ The micro-organisms were grown in a synthetic medium as described in Nichols et al. (15) where extent of growth was determined by titration of acid produced. Extent of growth is expressed on the basis of the number of milliliters of $0.1 \mathrm{M} \mathrm{NaOH}$ used to back-titrate the acid produced by bacteria grown in $5 \mathrm{ml}$ medium for $40 \mathrm{hr}$ at $37^{\circ}$ in a $\mathrm{N}_{2}-\mathrm{CO}_{2}$ atmosphere in the presence of $100 \mu \mathrm{g}$ material tested.

Glycoprotein B was apparently a mixture of several small moleuclar weight components. Because of this heterogeneity, the determination of the "molecular weight" of the fraction is devoid of a precise meaning. However, these experiments were done and are reported herein simply to indicate that the components of glycoprotein fraction B were much smaller in size than was glycoprotein A. Because glucose was found in glycoprotein B (Fig. 3 ), it is not unreasonable to assume that one of the components of this fraction was the nondialyzable oligosaccharide studied by György et al. (10), which was a poor L. bifidus growth promoter in the native state, but acquired such growth-promoting activity upon being desialized. Glycoprotein B exhibited precisely the same behavior.

This paper then supports our previous suggestion (15) to the effect that human milk and colostrum contain nondialyzable $L$. bifidus growth-promoting factors of at least two types: those that stimulate the bacterial growth in their native state, and those that do so when the sialic acid is removed. The former are glycoproteins in nature, whereas the latter are oligosaccharides.

\section{SUMMARY}

Two homogeneous glycoproteins were isolated from mature human milk whey. One proved to be identical with human serum orosomucoid, the other was apparently specific to milk. The latter glycoprotein had a molecular weight of 29,500 , and contained near $70 \%$ carbohydrate consisting of galactose, glucosamine, galactosamine, fucose, and sialic acid. It was also a potent promoter of the growth of L. bifidus var. Penn. Human milk whey was shown to contain additional glycoproteins, which were isolated as a mixture, and whose average molecular weight was near 4,000. This mixture of glycoproteins was a poor growth-promoting agent for L. bifidus var. Penn., although its activity increased after desialization. 
REFERENCES AND NOTES

1. Anderson, B., Hoffman, P., and Meyer, K.: The $O$-serine linkage in peptides of chondroitin 4- or 6-sulfate. J. Biol. Chem., 240: 156 (1965)

2. Bezkorovainy, A.: Some physical and chemical properties of an M-2 glycoprotein isolated from normal bovine plasma. Biochemistry, 2: 10 (1963).

3. Bezkorovainy, A.: Comparative study of the acid glycoproteins isolated from bovine serum, colostrum, and milk whey. Arch. Biochem. Biophys., 110: 558 (1965).

4. Bezkorovainy, A., and Doherty, D. G.: Isolation and characterization of an acidic glycoprotein from normal bovine plasma. Arch. Biochem. Biophys., 96: 491 (1962).

5. Bezkorovainy, A., and Winzler, R. J.: Isolation and characterization of an acidic $\alpha_{2}$-glycoprotein. Biochim. Biophys. Acta, 49: 559 (1961).

6. Cheron, A.: Les globulines immunes de lait. Ann. Nutr. Alim., 25: A135-A179 (1971).

7. Dubois, M., Gilles, K. A., Hamilton, J. K., Rebers, P. A., and Smith, M.: A colorimetric method for determination of sugars and related substances. Anal. Chem., 28: 350 (1956).

8. Goldman, A. S., and Smith, C. W.: Host resistance factors in human milk, J. Pediat., 82: 1082 (1973)

9. György, P.: A hitherto unrecognized biochemical difference between human milk and cow's milk. Pediatrics, $11: 98$ (1953).

10. György, P., Jeanloz, R. W., von Nicolai, H., and Zilliken, F.: Undialyzable growth factors for Lactobacillus bifidus var. pennsylvanicus. Eur. J. Biochem., 43: 29 (1974)

11. Hanson, L. §., and Johansson, B. G.: Immunological studies of human milk. In H. A. McKenzie: Milk Proteins, Vol. 1, p. 65 (Academic Press, New York, 1970)

12. Hirano, S., Hayashi, H., Terabayashi, T., Onodera, K., Iseki, S., Kochibe, N. Nagai, Y., Yagi, N., Nakagaki, T., and Imagawa, T.: Biologically active glycopeptides in human colostrum. J. Biochem., 64: 563 (1968),

13. Malpress, F. H., and Seid-Akhavan, M.: Studies on human $\alpha_{\mathbf{s}^{-}}$and $\kappa$-casein

Copyright (c) 1976 International Pediatric Research Foundation, Inc. fractions and human caseinoglycomacropeptide. Biochem. J., 101:764 (1966).

14. Nichols, J. H., and Bezkorovainy, A.: Isolation and characterization of a glycoprotein from human colostrum. Biochem. J., 135: 875 (1973).

15. Nichols, J. H., Bezkorovainy, A., and Landau, W.: Human colostral whey M-1 glycoproteins and their $L$. bifidus var. Penn. growth promoting activities. Life Sci., 14: 967 (1974)

16. Querinjean, P., Masson, P. I., and Heremans, F.: Molecular weight, single chain structure, and amino acid composition of human lactoferrin. Eur. J. Biochem. 20: 420 (1971).

17. Schachman, H. K.: Ultracentrifugation, diffusion, and viscometry. Methods Enzymol., 4: 32 (1957).

18. Winzler, R. J.: Determination of serum glycoproteins. Methods Biochem. Anal., 2: 279 (1955).

19. Zschocke, R., and Bezkorovainy, A.: Some immunochemical properties of succinylated human transferrin and related proteins. Biochim. Biophys. Acta, 200: 241 (1970)

20. Zschocke, R., Grieble, H. G., Bach, G. I., and Anderson, T. O.: Studies on IgA I. Fractionation procedure for isolation of $\mathrm{IgA}$ from pooled normal human plasma. J. Immunol., 102: 625 (1969).

21. Los Angeles, Calif

22. Piscataway, N. J.

23. St. Louis, Mo.

24. Detroit, Mich

25. Chicago, Ill.

26. This work was supported by Grant no. HD-05657-03 from the National Institutes of Health, United States Public Health Service. Many thanks due to $C P$ for her generous milk donations and to the Evanston Hospital Milk Bank (c/o Department of Pediatrics) for their fine cooperation.

27. Requests for reprints should be addressed to: A Bezkorovainy, Ph.D., Depart ment of Biochemistry, Rush-Presbyterian-St. Luke's Medical Center, Chicago, I11. 60612 (USA).

28. Accepted for publication July 10, 1975

Printed in U.S.A.

Pediat. Res. 10: 5-10 (1976)

Decanoic acid

fatty acids

hexanoic acid placenta protein binding

\title{
Transfer across Perfused Human Placenta. IV. Effect of Protein Binding on Free Fatty Acids
}

\author{
JOSEPH DANCIS, ${ }^{(16)}$ VALERIE JANSEN, AND MORTIMER LEVITZ \\ Departments of Pediatrics and Obstetrics and Gynecology, New York University School of Medicine, New York,
} New York, USA

\section{Extract}

The effect of protein binding on the rate of placental transfer of hexanoic ( $\mathrm{C} \mathrm{6}$ ) and decanoic ( $\mathrm{C} \mathrm{10}$ ) acids was investigated in an in vitro perfusion system of human placenta. As much as $30 \%$ of transferred $\mathrm{C} 6$ was converted to more polar compounds, so that the observations related to the combined effects on transfer and metabolism. Less than $10 \%$ of $\mathrm{C} 10$ was similarly metabolized. Both fatty acids are soluble in buffered salt solutions at the concentrations used $(40 \mu \mathrm{M})$ and both are bound to serum albumin, $C-10$ having higher association constants $\left(K^{\prime}\right.$ for $C 6,1.48 \times 10^{4}$; for $\left.\mathrm{C} 10,1.03 \times 10^{5}\right)$. When the placenta is perfused with buffered salt solution, the transfer of $\mathrm{C} 6$ is $22 \%$ more rapid than that of $\mathrm{C}$ 10. It is suggested that binding within the placenta retards $C 10$ more than $C 6$. The addition of $1 \mathrm{~g} / 100 \mathrm{ml}$ bovine serum albumin to the maternal perfusate reduces the transfer rate of $\mathrm{C} \mathbf{1 0}$ by $\mathbf{8 0 \%}$, whereas $2 \mathrm{~g} / 100 \mathrm{ml}$ serum albumin has a more moderate effect on $\mathrm{C}$ 6 (a reduction of $50 \%$ ). The addition of $1 \mathrm{~g} / 100 \mathrm{ml}$ serum albumin to the fetal perfusate increases transfer rate of both free fatty acids (FFA), C 6 by about $25 \%$ and C 10 by about $250 \%$. With equiva- lent concentrations of serum albumin in maternal and fetal perfusates, the transfer rate of $\mathrm{C} 10$ was reduced by $65 \%$, whereas there was no detectable effect on transfer of $\mathrm{C} 6$ in two of three experiments.

The transfer rates of FFA increase logarithmically with progressive shortening of the carbon chain from $\mathrm{C} 16$ to $\mathrm{C} 8$ when maternal and fetal perfusates contain serum albumin. Protein binding is apparently the determining factor. The rate of transfer falls off at $\mathrm{C}$ 6 and $\mathrm{C} \mathrm{4}$, even though protein-binding continues to decrease. The determining factor may be the hydrophilic nature of these molecules.

\section{Speculation}

If the observations on FFA have general applicability, the overall effect of protein binding on placental transfer of a particular substance may relate to its water solubility and protein binding. If water solubility is not a limiting factor, protein binding may decrease transfer rate sharply, as occurs with decanoic acid (C 10). With substances that have very limited water solubility, protein 